\title{
Perennial Rye: Genetics of Perenniality and Limited Fertility
}

\author{
Paul Gruner and Thomas Miedaner*(D) \\ State Plant Breeding Institute, University of Hohenheim, 70593 Stuttgart, Germany; \\ Paul.Gruner@uni-hohenheim.de \\ * Correspondence: miedaner@uni-hohenheim.de; Tel.: +49-711-4592-2690
}

Citation: Gruner, P.; Miedaner, T.

Perennial Rye: Genetics of

Perenniality and Limited Fertility.

Plants 2021, 10, 1210. https://

doi.org/10.3390/plants10061210

Academic Editor:

Ioannis Ganopoulos

Received: 6 May 2021

Accepted: 11 June 2021

Published: 14 June 2021

Publisher's Note: MDPI stays neutral with regard to jurisdictional claims in published maps and institutional affiliations.

Copyright: (C) 2021 by the authors. Licensee MDPI, Basel, Switzerland. This article is an open access article distributed under the terms and conditions of the Creative Commons Attribution (CC BY) license (https:// creativecommons.org/licenses/by/ $4.0 /)$.

\begin{abstract}
Perenniality, the ability of plants to regrow after seed set, could be introgressed into cultivated rye by crossing with the wild relative and perennial Secale strictum. However, studies in the past showed that Secale cereale $\times$ Secale strictum-derived cultivars were also characterized by reduced fertility what was related to so called chromosomal multivalents, bulks of chromosomes that paired together in metaphase I of pollen mother cells instead of only two chromosomes (bivalents). Those multivalents could be caused by ancient translocations that occurred between both species. Genetic studies on perennial rye are quite old and especially the advent of molecular markers and genome sequencing paved the way for new insights and more comprehensive studies. After a brief review of the past research, we used a basic QTL mapping approach to analyze the genetic status of perennial rye. We could show that for the trait perennation 0.74 of the genetic variance in our population was explained by additively inherited QTLs on chromosome $2 R, 3 R, 4 R, 5 R$ and $7 R$. Fertility on the other hand was with 0.64 of explained genetic variance mainly attributed to a locus on chromosome $5 \mathrm{R}$, what was most probably the self-incompatibility locus S5. Additionally, we could trace the Z locus on chromosome $2 \mathrm{R}$ by high segregation distortion of markers. Indications for chromosomal co-segregation, like multivalents, could not be found. This study opens new possibilities to use perennial rye as genetic resource and for alternative breeding methods, as well as a valuable resource for comparative studies of perennation across different species.
\end{abstract}

Keywords: Secale cereale; Secale montanum; Secale strictum; QTL mapping; molecular marker; selfincompatibility; fertility; seed set

\section{Introduction}

In 2019, rye was grown on about 4.2 million hectares worldwide resulting in an overall production of about 12.8 million tons [1]. This data, however, must be mainly based on annual rye (Secale cereale L.) because only a limited number of perennial rye (Secale cereale $\times$ Secale strictum) cultivars were available and to our knowledge the last breeding efforts were done more than a decade ago. According to the original habitat of Secale strictum Presl. (syn. Secale montanum Guss.) in dry, stony or sandy mountain areas or as weed in or along cultivated fields [2], the breeding goal for perennial rye was to develop cultivars for poor and sandy soils that could be used as forage [3-5] or as soil cover and (especially winter) pasture for solely grazed areas [6] or combined as fodder and grain crop in low-input farming $[7,8]$. Beside high drought (and cold) tolerance more traits of S. strictum were interesting for breeding: large root systems, high tillering capacity, weed suppression, pest resistances, tolerance to (heavy) metals like nickel, zinc, aluminum and manganese and high protein content of kernels [2,9-11].

Secale cereale $\times$ Secale strictum crosses aiming for establishing perennial rye cultivars were made by several groups worldwide. Reimann-Phillipp in Germany released two tetraploid varieties 'Permontra' (winter type) and 'Sopertra' (spring type) and produced diploid breeding material that did not reach official variety registration [8], but was used in this study. Kruppa and Kotvics in Hungary released the varieties 'Kriszta' and 'Perenne' [3,5] and Myers in Australia produced the (non-registered) cultivar 'Black 
Mountain' [6]. The Letbridge Research and Developmental Centre in Canada developed the cultivar 'ACE-1' based on selections derived from Reimann-Philipp [4].

Compared to the annual S. cereale, all breeding efforts were confronted with fragile rachis (brittle ear), low grain yields, loose stands especially in the years after first harvest, low fertility, long periods of flowering and ripening and high ergot infections arising as consequence of the latter two in combination with wet weather conditions [4-8,10]. Crossing barriers between S. cereale and S. strictum were the main reason for the low fertility and cytological studies of pollen mother cells (PMCs) revealed abnormalities. In metaphase I (or anaphase) of the PMCs, where the sister chromatids usually pair together (= seven bivalents), often a multivalent of six chromatids (= three chromosomes in ring or line formation) plus four bivalents (= four chromosomes) was found and this indicated (two) translocations on the three multivalent-forming chromosomes (Figure 1a) [12-16].

(a)

S. cereale

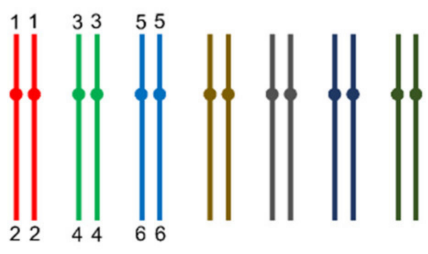

S. montanum
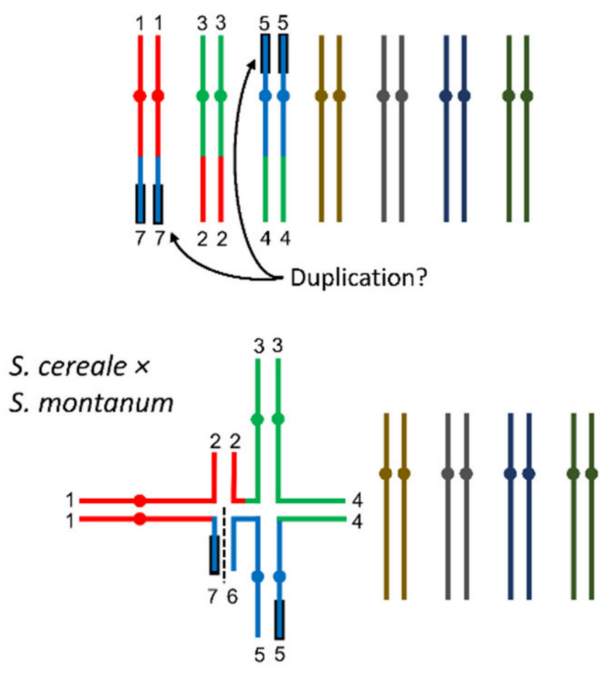

(b)

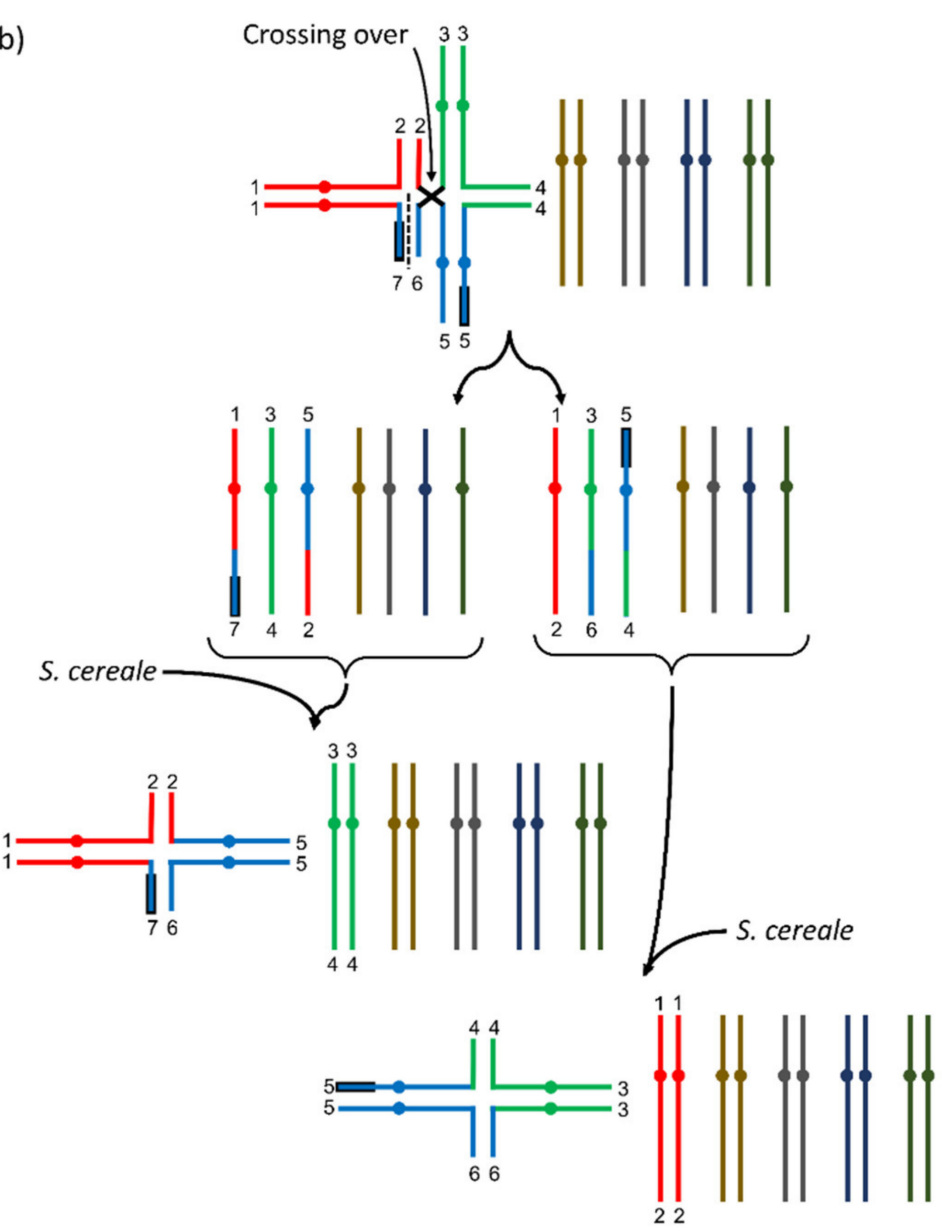

Figure 1. Visualization of multivalents in S. cereale $\times$ S. strictum progenies according to results from Stutz [17]. (a) In S. cereale $\times$ S. strictum a multivalent of six chromatids could be detected in metaphase I of pollen mother cells. This was caused by translocations between three chromosomes of the two parental species (in color). Following [17], the numbers indicate the chromosomal assignment, the black framing of the chromosomes indicates a potential duplication and the dashed line the separation point for chromosomal line configurations that were also observed. (b) In an $\mathrm{F}_{2}$-generation, in rare cases also multivalents with four chromatids could be observed. This could be explained by a crossing over within the ring conformation (top). When the resulting gametes (two possible configurations) were then combined with $S$. cereale gametes, two differently composed four-chromosome multivalents could be formed and another two different compositions would be possible when they would be combined with the S. strictum gametes. Here, only the combination with $S$. cereale gametes is shown and more details can be found in [17]. 
With low frequency, even more chromosomal constitutions could be identified in the progenies [12-14,16], however, some of the results had to be questioned [17] because S. strictum accessions that were used showed multivalents also for plants of wild S. strictum, which was in disagreement with the other authors listed before. The phenomenon of multivalent formations and explanations for the different constitutions were best described in Stutz [18] and Dierks and Reimann-Philipp [19]. The important link between low fertility and chromosomal translocations was the assumption that DNA of all seven chromosomes was required for a viable gamete. The arbitrary segregation of the six multivalent chromosomes would only result in fertile gametes when all three chromosomes of a single parental species would segregate together. If the arbitrary segregation of the chromosomes of the multivalent was considered, Dierks and Reimann-Philipp [19] calculated that functional chromosomal constitutions could be expected in 25 percent of the cases only. Additional fertility problems of $S$. strictum and potential fertile abnormal chromosomal constitutions may had influenced this theoretical ratio in a way that fertility assessment of microgametes (pollen) and macrogametes (kernels/inflorescences) often exceeded the theoretical expectation calculated from chromosomal segregation ratios [12,19].

Aside of cytogenetically caused non-fertility in the $S$. cereale $\times$ S. strictum progenies, we added another fertility-related factor in our experiment by crossing a self-incompatible $S$. cereale $\times S$. strictum genotype with a self-fertile inbred line. The cultivated rye $S$. cereale is generally a self-incompatible cross-pollinating species, but self-fertile genotypes (resulting in inbred lines) were developed by recurrent selection of partially self-fertile plants detected in extremely large populations ( $\mathrm{N}>50,000)$ [20]. The self-incompatibility in rye has been referred to gametophytic mechanisms and interaction of two loci named $S$ and $Z$ [21] and two loci on chromosome $1 R$ and $2 R$ have been referred to those genes [22-24]. The genes for self-fertility (or pseudocompatibility) have been referred to the same loci [25,26] and selffertility can be interpreted as special allele $S f$ of the self-incompatibility locus $[27,28]$. Aside of the $S$ and Z loci (= S1 and S2 loci), a further self-fertility locus S5 was located on chromosome $5 R[28,29]$. Even more dominant self-fertility genes were found on chromosomes $1 R$, $4 R, 5 R$ and 6R [29].

Based on microscopic studies, the chromosomes involved in multivalent formation were referred to $2 R, 6 R$ and $7 R$ [8] and due to the reasons listed before, the identification of any gene thereon would be challenging. For the perennial habit (perenniality), Dierks and Reimann-Philipp [19] concluded that a major (dominant) gene $P$ was located on one of the respective chromosomes. The fertility problems of all the breeding attempts with $S$. cereale $\times$ S. strictum progenies did support this hypothesis and the only disagreement with this theory coming from Stutz [18], could be regarded to the misinterpretation of the perennial phenotype. Other traits like the fragile rachis ("brittle ears") typical for S. strictum, or spring/winter type (vernalization requirement for flower induction) when crossed with spring-type $S$. cereale were inherited independently from the multivalent according to Dierks and Reimann-Philipp [19], however, also close correlation of perenniality and fragile rachis had been observed in experiments where only $1 \%$ of the $\mathrm{F}_{2}$-plants showed perenniality without fragile rachis [20].

Nevertheless, recombination was also observed between the homologous chromosomal segments of the multivalent. Thus, if the perenniality gene $P$ would be located at a (distal) chromosomal position where still recombination occurred, it must be possible to identify perennial $S$. cereale recombinants. If there would be no crossing over between a $P$-carrying $S$. strictum chromosome and a $S$. cereale chromosome resulting in viable gametes, the mapping of the perenniality gene would be impossible with classical crossing experiments and consequently, the breeding of fertile perennial rye varieties would require homozygosity for all three translocated S. strictum chromosomes [18,19]. Even further, any introgression of $S$. cereale would disturb this configuration and lead again to a high percentage of non-viable gametes and hence reduced fertility. However, Stutz [18] found another multivalent constitution by analyzing a $\mathrm{F}_{2}$ generation. There, single genotypes showed pollen mother cells with only four chromatids ( $=2$ chromosomes) and five re- 
maining bivalents in metaphase I. This could be explained by a crossing over across the six-chromatid ring multivalent in the $\mathrm{F}_{1}$ plants (Figure $1 \mathrm{~b}$ ). These configurations would be especially valuable for genetic studies and breeding, because two possible configurations of four-chromosome multivalents with different chromosomes involved could theoretically occur (Figure 1b) and thus it would allow to identify the respective chromosomes and with further crossing and recombination steps also the gene loci.

To our knowledge, the last genetic studies of perennial rye were at the methodological level of chromosome microscopy, but perenniality (and fertility) was also studied in other cereals (rice, sorghum, maize, wheat) and their perennial wild relatives by means of molecular markers [30-36] and sequence based genomics and transcriptomics [37-40]. All those studies showed that the genetics of perenniality was highly complex. Several QTLs and even more gene candidates, of which often several could be located in one single QTL were found. Interestingly, almost all loci that were identified independently in the separate species could be connected through syntenic gene motifs (DNA and protein sequences) across the species, showing that this trait was highly conserved between the species.

For this study, a $F_{2}$ population originating from crossing an annual and self-fertile inbred line with a perennial and self-incompatible plant from an improved perennial population that was originally derived from breeding material of Reimann-Philipp [8] was phenotypically assessed for perenniality and fertility and genomically with an Infinium iSelect 10K SNP-chip. At first, we present the phenotypes for both traits separately and the relation between them, then results from studying the pure marker data in regard to multivalents and other abnormalities and finally the QTL-mapping results for both traits.

\section{Results}

\subsection{Phenotype}

For both traits, perenniality and fertility, a high amount of genetic variance was observed (Table 1). Perenniality (1-9) was assessed at two sites, but the maximum value of 9 was only recorded once for a single plant and the maximum calculated BLUE was 8 (Figure 2). Most of the phenotypic variance was explained by the genotype, but also the genotype-location interaction was high (Table 1).

Table 1. Variance components (Var.comp.) with standard errors (St. Error) and entry-mean heritability $\left(\mathrm{H}^{2}\right)$ for the traits perenniality (scored in 1-9 scale) and fertility (scored from 0 to $100 \%$ ). Fertility was assessed in one location and hence some factors could not be assessed (n.a.).

\begin{tabular}{ccccc}
\hline & \multicolumn{2}{c}{ Perenniality (1-9) } & \multicolumn{2}{c}{ Fertility (0-100\%) } \\
\hline & Var. Comp. & St. Error & Var. Comp. & St. Error \\
\hline Location (L) & 0.22 & 0.39 & n.a. & n.a. \\
Replicate & 0.08 & 0.09 & 2.6 & 4.4 \\
Genotype (G) & 3.72 & 0.51 & 313.7 & 38.9 \\
G $\times$ L & 1.18 & 0.21 & n.a. & n.a. \\
Residual & 1.39 & 0.10 & 94.9 & 9.5 \\
\hline $\mathrm{H}^{2}$ & & 0.81 & & \multicolumn{2}{c}{0.87} \\
\hline
\end{tabular}

The lowest observation for fertility was $10 \%$, but only a few plants showed this low fertility and all estimated BLUES were higher than 20\% (Figure 2). Most of the phenotypic variance was explained by the genotype but no genotype-location interaction could be calculated. For both traits, the entry-mean heritability was high (0.81 and 0.87) but the phenotypic distributions were non-normal (Figure 2). Correlation between both traits was only moderate (0.37). This and the observation of highly perennating genotypes combined with high fertility (Figure 2) indicated an incomplete linkage of both traits. The opposite off-correlation extreme, no perenniality and low fertility, could not be found indicating that still the annual genotypes were the most fertile. 


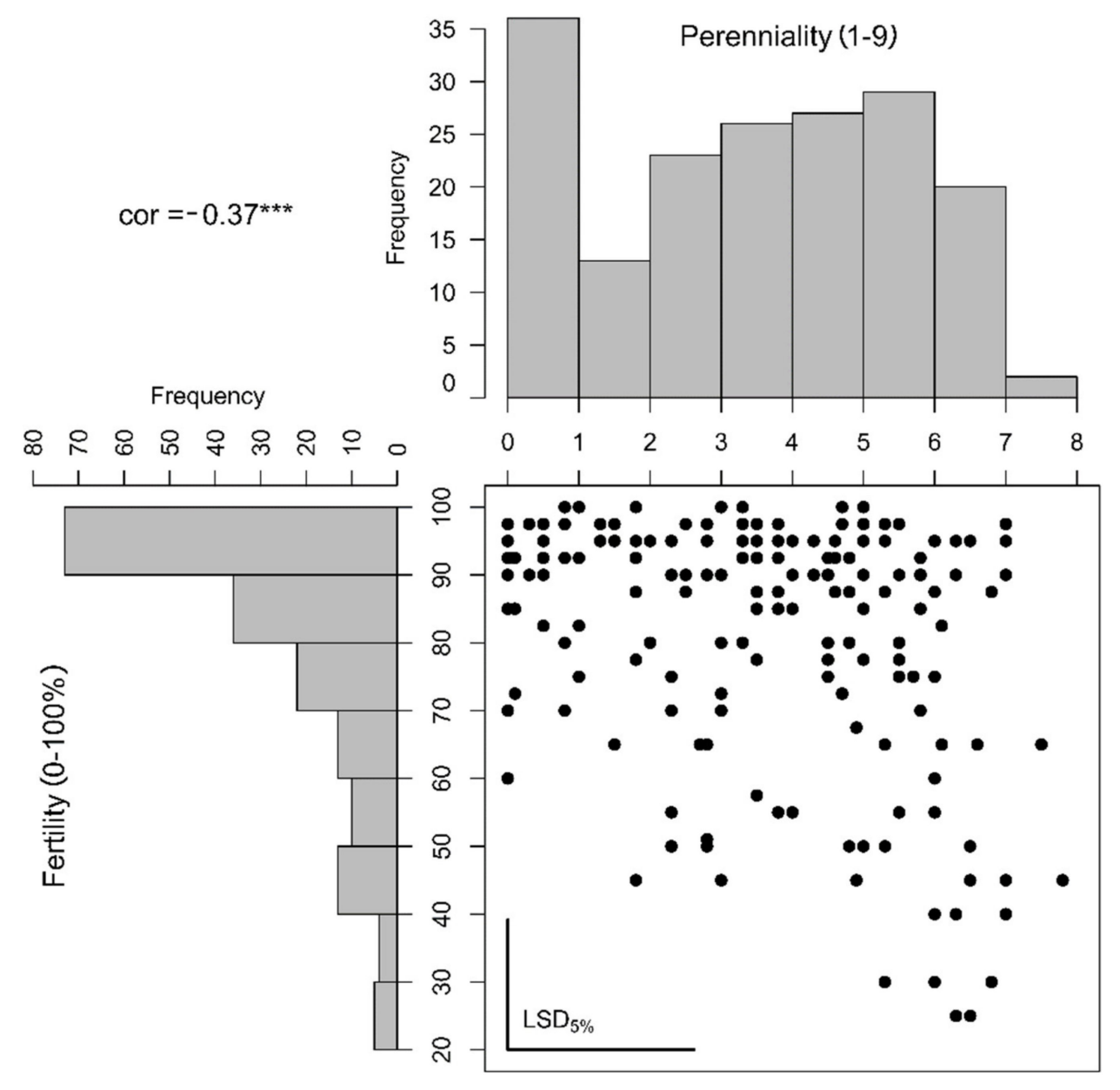

Figure 2. Histograms and correlation plot based on the estimated genotypic means (best linear unbiased estimators, BLUES) of perenniality (scored from 1 to 9 ) and non-fertility (scored from 0 to $100 \%$ ). The calculated correlation (cor) was estimated to be -0.37 and highly significant with $\alpha \leq 1 \%$ ${ }^{* * *}$. The least-significant differences (LSD) on $\alpha \leq 5 \%$ significance level were plotted as bars in the bottom-left corner of the correlation plot.

\subsection{Marker Studies}

The study of pure marker data had two purposes. Firstly, this was the basis for QTL mapping and secondly, we could use it to find indications for chromosomal abnormalities like multivalents that would had directly influenced fertility. We could successfully apply the Infinium iSelect SNP chip that was initially developed for S. cereale, for a S. cereale $\times$ S. strictum population. After filtering, 2641 markers remained from the 10K SNP assay and entered into the analysis. Caused by the few possible recombination events generally observable in $\mathrm{F}_{2}$-generations, 2314 markers were intercorrelated with one (=redundant), many in several combinations, resulting in 789 unique markers. For those, the " $\mathrm{A}$ " marker allele had a frequency of $25.5 \%$ on average, the " $\mathrm{B}$ " allele of $22.8 \%$, the heterozygous of $51.5 \%$ and the missing values $0.1 \%$. A linkage map could be constructed and except for some chromosomal regions, it covered the full genome when compared with overlapping markers $(n=812)$ from a previously published linkage map [41] (Figure 3). Some chromosomal regions (on 2R, 3R, 5R and 7R) were less covered with molecular markers compared to the previously published map (Figure 3). However, the map from Bauer et al. [41] had many more markers $(\mathrm{N}=87,820)$ and no (large) differences in the marker order of both maps were observed so that our map was still considered sufficient for the linkage mapping. 


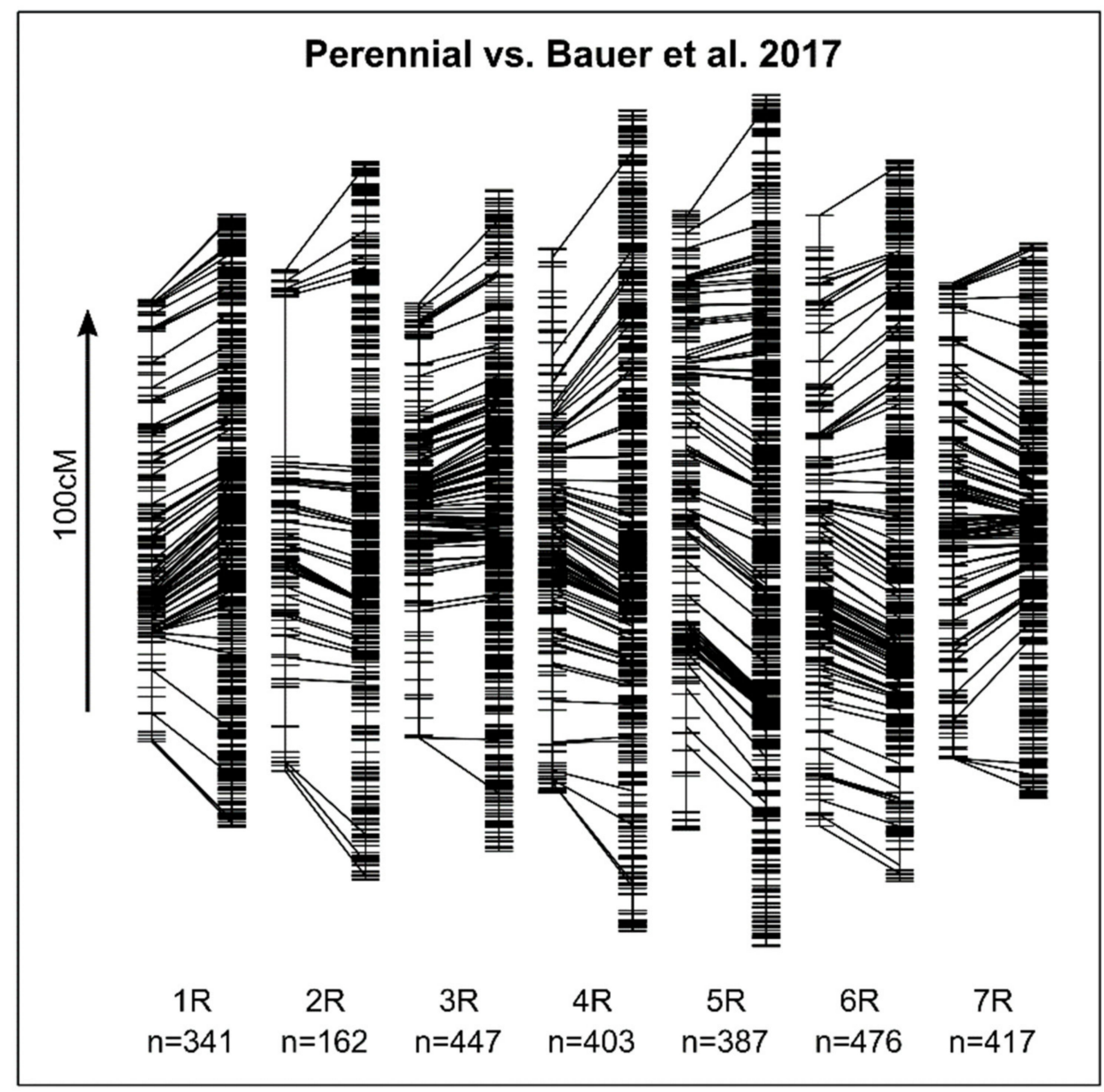

Figure 3. Chromosome-wise comparison of a linkage map constructed from the marker data analyzed here (Perennial, left) with a previously published linkage map [41] (right). Overlapping markers of the respective linkage groups $(1 \mathrm{R}-7 \mathrm{R})$ are connected by lines. For comparisons of the absolute sizes in $\mathrm{cM}$, an arrow indicating the chromosomal order with a length of $100 \mathrm{cM}$ is displayed in the left of the plot. The number of markers in each linkage group of the constructed linkage map (Perennial) is reported (n).

The largest gap on the top arm of chromosome $2 \mathrm{R}$ was also characterized by high segregation distortion, where the " $\mathrm{B}$ " marker alleles were reduced to zero resulting in a 1:1 ratio for the " $\mathrm{A}$ " and " $\mathrm{H}$ " allele. The full reduction of the " $\mathrm{B}$ " marker allele at zero could not be visualized in Figure 4, because we filtered the marker data set in a first step (before linkage map construction). If we used a linkage map based on other material like the one from Bauer et al. [41], the gap would be flanked by the markers isotig16940 at $114.7 \mathrm{cM}$ and C3277_855 at $124.3 \mathrm{cM}$. We referred this locus to the self-incompatibility locus $Z[23,24]$ what is probably equal to the self-fertility locus $S 2[25,26]$. The missing of the " $B$ " allele and segregation ratio of 1:1 for the " $A$ " and " $\mathrm{H}$ " allele agreed well with a self-fertility model with pollen compatibility [28] and previously reported segregation ratios [25]. Segregation distortion to a lower extend could also be observed at the top arms of chromosome $4 \mathrm{R}$ and $6 \mathrm{R}$, but it was considered irrelevant for following results. The successful construction of a linkage map was also an indicator that the linkage of markers was not influenced by chromosomal segregation abnormalities like multivalents. We further correlated all markers with each other and did not find any high correlation between markers of certain chromosomes (Figure S1) like it would be expected if only a certain parental chromosome (chromatid) combination would result in fertile gametes as proposed for example by Stutz [18] (Figure 1a). 
(a)

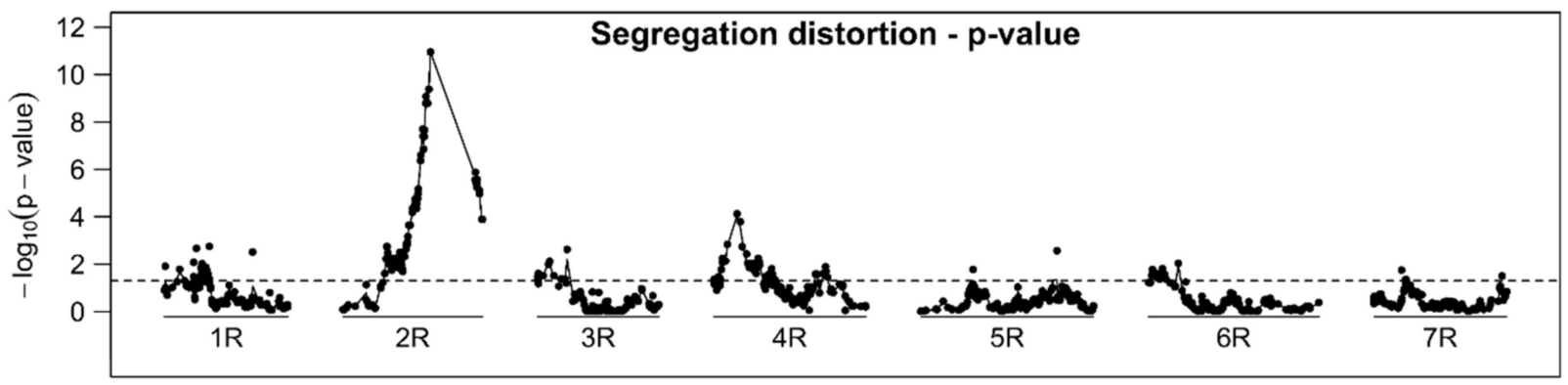

(b)

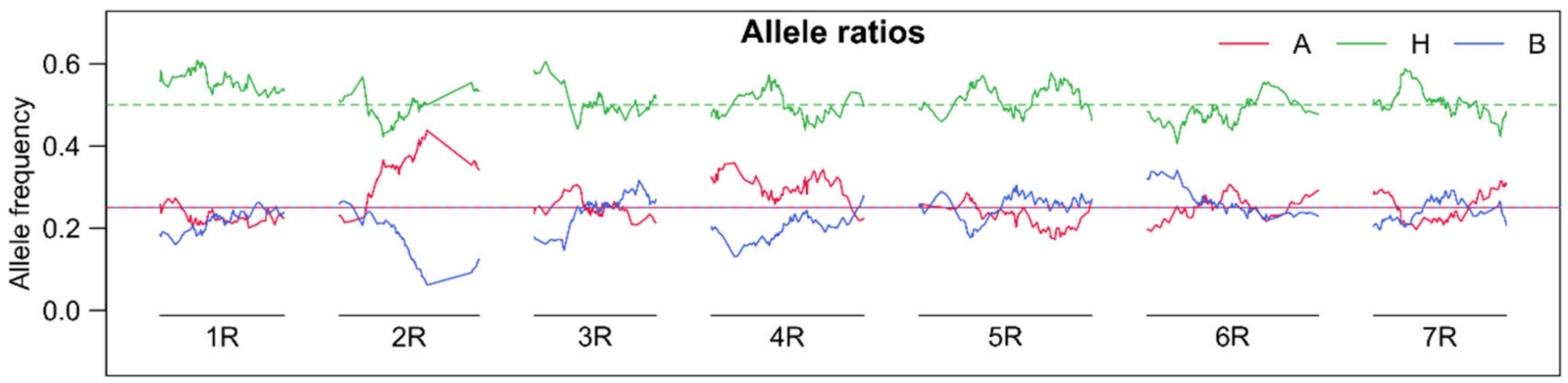

Figure 4. (a) Test of markers allele frequencies for distortion from the expected 1:2:1 (A, H, B) ratio of markers on the seven linkage groups (1R-7R). The $-\log _{10}$ of a Chi-square test is displayed. The horizontal dashed line gives a (unadjusted) global $5 \%$ threshold level. (b) The allele frequency for the respective marker alleles $(\mathrm{A}, \mathrm{H}, \mathrm{B})$ are displayed (red, green, blue) along the chromosomes. The horizontal lines give the expected frequencies 0.25 for the homozygous state (A, B) and 0.5 for the heterozygous state $(\mathrm{H})$. The lines were drawn by connecting single marker-based estimates.

\subsection{Mapping}

To detect markers associated with perenniality or fertility, we tested different procedures (scans) without marker cofactors and with differently selected cofactors and results were presented in Table 2 and Figures S2-S7, marker sequences can be found in Table S1. The cofactors and cofactor selection methods only marginally influenced the mapping results. Difference in detected loci between the methods could only be observed for the markers that explained the least variance in single marker fits (QTL-F1a, QTL-F1b, QTL-P2, QTL-P2).

For perenniality, three QTL were consistently found by all methods (Table 2). They were located on chromosome $4 \mathrm{R}$ (QTL-P4), chromosome 5R (QTL-P5) and chromosome 7R (QTL-P7). Those QTLs also explained most of the genetic variance, each $0.16,0.23$ and 0.24 , respectively. The effects for the first two were mainly codominant with effect sizes of 1.15 and 1.34, whereas the latter was dominant $(\mathrm{d}$ effect $=\mathrm{cd}$ effect $)$ or even over-dominant (d effect $>c d$ effect), i.e., having a codominant effect of 0.64 and a dominant effect 1.61 . All QTL (QTL-P2 to QTL-P7) were highly additive as the explained genetic variance of a model with markers from all QTL together was 0.74 and exactly the same as when explained variances of the single marker fits would be summed up. When combinations of the three QTLs explaining most of the variance (QTL-P4, QTL-P5, QTL-P7) were compared (Figure 5a), the genotypes having all three wild type alleles ( $\mathrm{H}$ or $\mathrm{B}$ ) had the highest perenniality followed by genotypes with two wild type alleles of which the combinations of QTL-P4 with QTL-P5 and QTL-P5 with QTL-P7 were on average higher than the combination of QTL-P4 with QTL-P7 (Figure 5a). However, for all combinations also genotypes with only little or even no perennation could be found (Figure S8). 


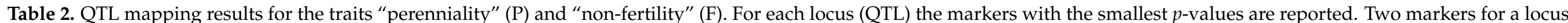

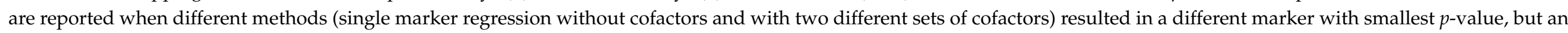
overlapping locus.

\begin{tabular}{|c|c|c|c|c|c|c|c|c|c|c|c|c|c|c|c|c|c|c|}
\hline Name & Marker & Chr. & Pos. & CI L & CI R & Pos. [41] & Pval c & Pval d & Pval cd+d & Eff. cd & SE cd & Eff. $d$ & SE d & $\mathrm{n}_{\mathrm{A}}$ & $\mathrm{n}_{\mathrm{B}}$ & $\mathrm{n}_{\mathrm{H}}$ & $\mathrm{p}_{\mathrm{G}}$ & $\mathrm{p}_{\text {CovG }}$ \\
\hline \multicolumn{19}{|c|}{ Perenniality } \\
\hline QTL-P2 & Contig1964 a & 2 & 121.0 & $79.2^{\mathrm{a}}$ & $123.3^{a}$ & $153.6 *$ & $6.4 \times 10^{-1}$ & $1.7 \times 10^{-4}$ & $3.6 \times 10^{-5}$ & -0.69 & 0.42 & 1.32 & 0.30 & 62 & 18 & 96 & 0.07 & 0.00 \\
\hline QTL-P3 & isotig $21327^{b, c}$ & 3 & 71.1 & $66.9^{c}$ & $73.3^{c}$ & 100.5 & $1.0 \times 10^{-2}$ & $2.9 \times 10^{-1}$ & $3.0 \times 10^{-1}$ & 0.58 & 0.19 & 0.34 & 0.27 & 45 & 44 & 87 & 0.04 & -0.08 \\
\hline QTL-P4 & Contig1605 b,c & 4 & 74.6 & $72.0^{c}$ & $75.4^{c}$ & $94.7 *$ & $1.5 \times 10^{-7}$ & $7.6 \times 10^{-1}$ & $5.2 \times 10^{-6}$ & 1.11 & 0.18 & 0.14 & 0.39 & 51 & 41 & 84 & 0.16 & 0.33 \\
\hline QTL-P5 & C14811_2522 a,b,c & 5 & 77.0 & $71.9^{\mathrm{a}}$ & $80.8^{a}$ & 88.8 & $8.6 \times 10^{-11}$ & $9.2 \times 10^{-1}$ & $6.4 \times 10^{-8}$ & 1.34 & 0.17 & -0.04 & 0.29 & 40 & 49 & 87 & 0.23 & 0.39 \\
\hline QTL-P7 & isotig17332 a,b,c & 7 & 0.6 & $0.0^{\mathrm{a}}$ & $2.3^{\mathrm{a}}$ & $1.2 *$ & $3.4 \times 10^{-4}$ & $5.5 \times 10^{-7}$ & $4.8 \times 10^{-8}$ & 0.64 & 0.18 & 1.61 & 0.27 & 50 & 36 & 90 & 0.24 & 0.09 \\
\hline \multicolumn{17}{|c|}{ Contig1964 + isotig21327 + C9941_1700 + C14811_2522 + isotig17332 } & 0.74 & 0.80 \\
\hline \multirow{2}{*}{ QTL-F1a } & isotig11337 b & 1 & 29.7 & $27.2^{\mathrm{b}}$ & $30.6^{\mathrm{b}}$ & $62.7^{*}$ & $9.1 \times 10^{-4}$ & $2.0 \times 10^{-1}$ & $3.4 \times 10^{-4}$ & -7.2 & 0.23 & 3.6 & 0.30 & 37 & 36 & 103 & 0.06 & 0.14 \\
\hline & isotig22259 c & 1 & 33.9 & $30.6^{c}$ & $34.8^{\mathrm{c}}$ & $68.3 *$ & $1.3 \times 10^{-2}$ & $1.4 \times 10^{-1}$ & $2.5 \times 10^{-3}$ & -5.8 & 0.24 & 4.2 & 0.30 & 37 & 32 & 107 & 0.04 & 0.11 \\
\hline QTL-F1b & Contig1017 a & 1 & 63.2 & $59.3^{\text {a }}$ & $66.6^{\mathrm{a}}$ & $91.6 *$ & $1.7 \times 10^{-4}$ & $3.0 \times 10^{-3}$ & $3.2 \times 10^{-6}$ & -7.7 & 0.22 & 8.1 & 0.29 & 37 & 38 & 101 & 0.12 & 0.17 \\
\hline \multirow{2}{*}{ QTL-F4 } & isotig03456 ${ }^{\mathrm{a}}$ & 4 & 78.2 & $69.2^{\mathrm{a}}$ & $87.7^{\mathrm{a}}$ & 103.1 * & $2.7 \times 10^{-5}$ & $7.7 \times 10^{-3}$ & $1.7 \times 10^{-6}$ & -7.3 & 0.20 & -7.2 & 0.29 & 53 & 38 & 85 & 0.13 & 0.29 \\
\hline & Contig1437 b,c & 4 & 86.2 & $83.3^{c}$ & $87.1^{\mathrm{c}}$ & $126.5^{*}$ & $1.6 \times 10^{-5}$ & $2.4 \times 10^{-1}$ & $1.3 \times 10^{-5}$ & -7.9 & 0.20 & -3.2 & 0.29 & 37 & 41 & 82 & 0.11 & 0.25 \\
\hline QTL-F5 (S5) & C28789_183 a,b,c & 5 & 41.7 & $40.6^{\mathrm{a}}$ & $42.0^{\mathrm{a}}$ & $44.9^{*}$ & $2.8 \times 10^{-37}$ & $5.5 \times 10^{-15}$ & $9.5 \times 10^{-33}$ & -18.4 & 0.14 & 14.9 & 0.20 & 48 & 38 & 90 & 0.64 & 0.35 \\
\hline \multicolumn{17}{|c|}{ isotig11337 + Contig1017 + isotig03456 + C28789_183 } & 0.77 & 0.71 \\
\hline
\end{tabular}

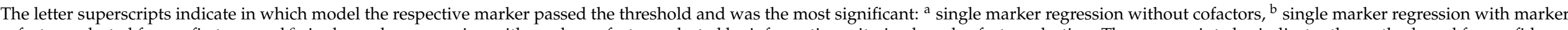

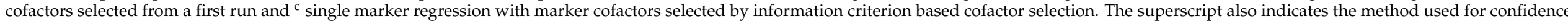

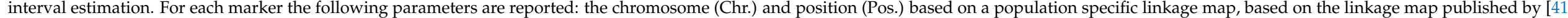

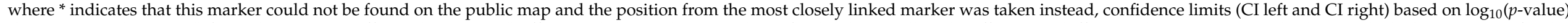

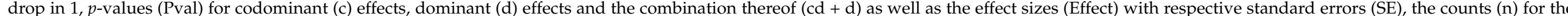

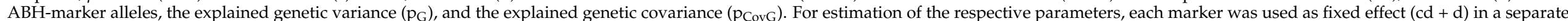
model and only for calculation of total explained variance a model was fitted combining $\mathrm{cd}+\mathrm{d}$ effects of all markers simultaneously. 

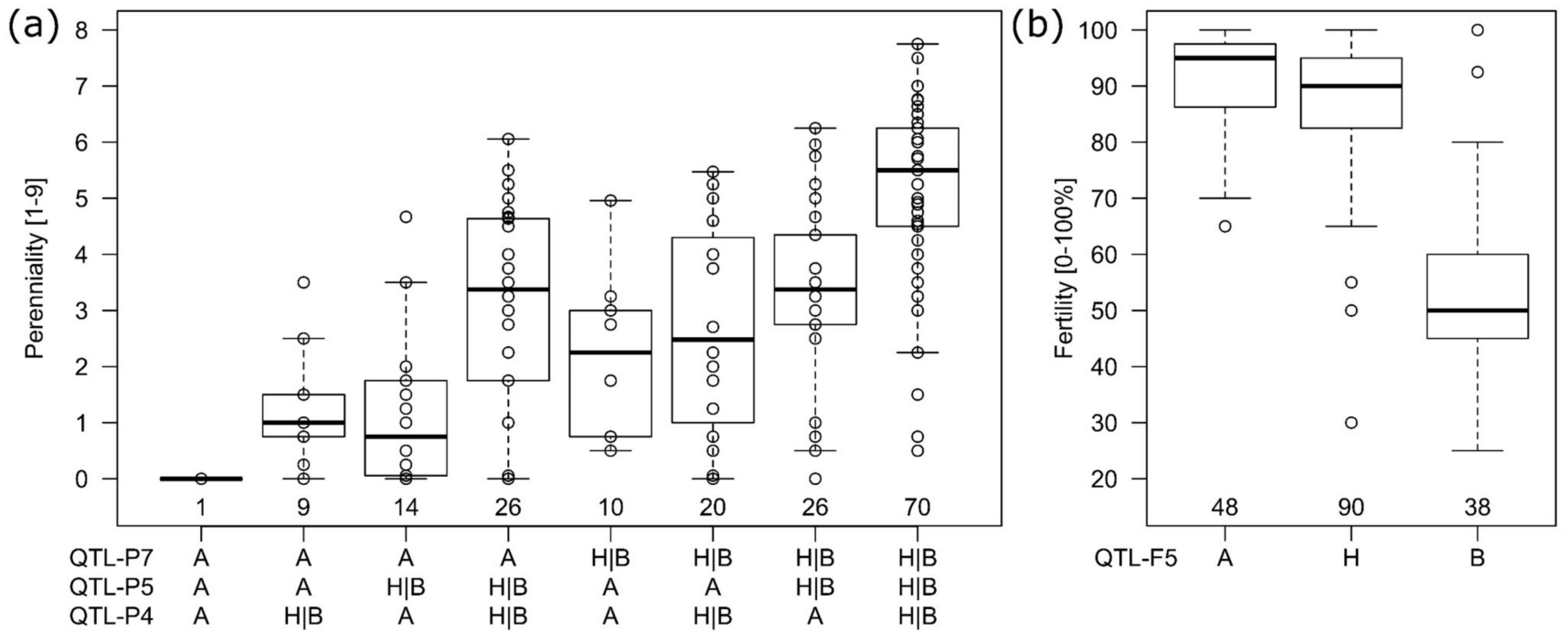

Figure 5. Genotypic means for perenniality (a) and fertility (b) clustered by marker alleles A, H and B ( $x$-axis) of the most significant markers in the respective QTLs. For perenniality (a) the $\mathrm{H}$ and B allele was combined in one group (H।B) and all genotype means were additionally plotted as dots in the boxplot display (box at first and third quartile with median in center). The number of genotypes with the respective marker allele combinations is written above the $x$-axis within the plot.

The trait fertility was mainly explained by a major QTL (QTL-F5) on chromosome $5 R$ explaining 0.64 of the genetic variance (Table 2, Figure $5 b$ ). The codominant effect was -18.4 and the dominant effect with 14.9 almost as high as the codominant. The negative effect size indicated that the A allele (inbred line) was leading to higher fertility (Figure $5 b$ ). More QTLs (QTL-F1a, QTL-F1b, QTL-F4) on chromosome 1R and 4R could be found. The additional QTLs explained only 0.06 to 0.13 of the genetic variance, had smaller (negative) effect sizes and the (positive) dominant effects of QTL-F1a and QTL-F1b again indicated the fertility to be dominantly inherited by the parental A allele for those two loci.

Additionally to this basic QTL mapping approach, we studied epistatic effects in terms of marker-marker interactions (Figures S9-S14) and to detect those, all possible combinations with $c d-c d, d-d$ and cd-d marker interactions were tested in a model with the same markers as single (cd and d) main effects simultaneously. As this resulted in many more tests, we adjusted the global significance threshold. With this stricter threshold no significant marker-marker interactions could be found, except of some single neighboring markers on chromosome $4 \mathrm{R}$ with cd-d interaction being significant. Nevertheless, for both traits several chromosomal regions showed high $p$-values for marker-marker interactions, but only a few were associated with the main QTLs we found. We concluded that with the given study set-up (population size and phenotypic error) we could not infer any useful conclusion regarding epistasis. Anyway, a detailed visualization can be found in Figures S9-S14. We also estimated explained covariance of both traits for the respective QTLs, but the explained covariance estimated for each QTL (Table 2) was generally low and the largest influence on the explained genetic covariance for a single marker were QTL-F4, QTL-F5, QTL-P4 and QTL-P5 with values between 0.25 and 0.39 each.

\section{Discussion}

Our study revealed new insights into perenniality and fertility of S. cereale $\times$ S. strictum progenies and we could show that perenniality was a complex trait with several QTLs involved compared to fertility (or non-fertility) which was mainly caused by a self-fertility allele at a self-incompatibility locus coming from the perennial parent. We could not find any indications for abnormalities in chromosomal segregation (multivalents) and their relation to low fertility, but as this was intensively discussed in previous studies we will 
discuss it in more detail here. It will be followed by a discussion of the results from mapping fertility and perenniality. Due to the scarce genomic-related literature on perenniality in rye, we addressed the usefulness of results from other species (species sytheny) and finally ended in future breeding perspectives.

\subsection{Multivalents}

We could not find an ultimate explanation why we could not prove the presences of multivalents with molecular markers. It was most reasonable, that the perennial genotype that we had used as parent did not result in multivalents (anymore), because it belonged to an improved perennial population from Reimann-Phillipp, who continued (also privately) with perennial rye breeding after releasing his research works on this topic and his major selection criterium was high fertility. Stutz [18] showed a possible way out of multivalents (Figure 1b) where crossing overs between the chromosomes could reduce the initial six-chromatid multivalent into a four-chromatid multivalent and it may be possible that following recombination events would have even led to chromosomal constitutions without any multivalent. Additionally, recombination was observed between the chromosomes of the multivalent $[18,19]$ what additionally could had caused translocated chromosomal segments to become smaller and reduced the lethality for gametes with certain combinations of translocated chromosomes. Even further, not only the genetic resource itself but also the perennial $F_{1}$ plant was chosen based on high fertility from crosses that had been made with several perennial plants to develop the population under study. Even more could the (indirect) selection against the " $\mathrm{B}$ " allele at the self-incompatibility loci $Z$ have influenced the constitution of the respective population as it would be located on one of the multivalent forming chromosomes [8]. To further clarify this issue, again the chromosomes in metaphase I of the pollen mother cells must be (microscopically) studied. Unfortunately, the material used here was not maintained as inbred lines, but remaining kernels of the same cross are currently developed into inbred lines so that more seeds for future studies combining both, molecular markers and microscopy of metaphase chromosomes in pollen mother cells would be available. If we could show, that the crossing barrier in terms of multivalent formation was overcome (or not an issue at all), it would allow (the three multivalent forming chromosomes of) S. strictum to be used as new (secondary) rye breeding pool, what may be especially interesting in terms of disease or drought resistance. Surprisingly, in a diversity study based on molecular markers [42] a single variety Gonello (KWS Lochow), that was characterized by high frost tolerance, was related to S. strictum showing that this wild species may had already been used in annual rye breeding.

\subsection{Fertility}

The locus QTL-F5 could be identical with the $S 5$ locus $[25,26]$ and the high amount of explained genetic variance of this locus proved it to be the main reason for non-fertility. It was surprising, that even though we did not place isolation bags on the heads of the plants, we most probably detected a self-incompatibility locus (with a segregating self-fertility allele) to explain most of the genetic variance for fertility. The reason could be that the experiment was flowering 2-3 weeks later than the rye stand growing on the experimental station so that the main pollen cloud could not pollinate the experiment. Additionally, the genotypes were grown as single plants in a distance of each other (about $0.25 \mathrm{~m}$ ) so that also within the experiment cross pollination was reduced. Still, for confirmation of limited self-fertility it would be necessary to use isolation bags preventing any cross-pollination in future experiments. In this study, no genotype was completely sterile. In rye, there were several loci known for self-incompatibility, three of them were located on chromosome $1 R, 2 R$ and $5 R$ and reported most often [23-27] but also loci on $4 R$ and $6 R$ have been proposed [29]. When self-fertility is interpreted as a special allele $S f$ at those loci, we hypothesised that the expression of $S f$ lead to an universal (or complementary) structure resulting in successful pollination. However, the pollination was only successful when $S f$ was expressed in both, pollen and stigma. Important for the segregation of the respective 
alleles at both loci was that a pollen structure would be defined by one haplotype $(\mathrm{n}=1 \mathrm{x})$ and consequently no pollen with the " $\mathrm{B}$ " allele at locus $Z$ could fertilize the macrogamete. This resulted in a 1:1 ratio of the " $\mathrm{A}$ " and " $\mathrm{H}$ " allele at the $\mathrm{Z}$ locus, what was proven by marker segregation. The pistil surface on the other side was in diploid stage and here a single (dominant) " $\mathrm{A}$ " allele must had expressed the self-fertility as we could show by the respective effect sizes (Table 2, Figure 5b). We visualized our hypothesis in Figure 6. However, we never (microscopically) studied the growth of the pollen tube on the stigma and eventually also other mechanisms could prevent the fertilization of the macrogamete.

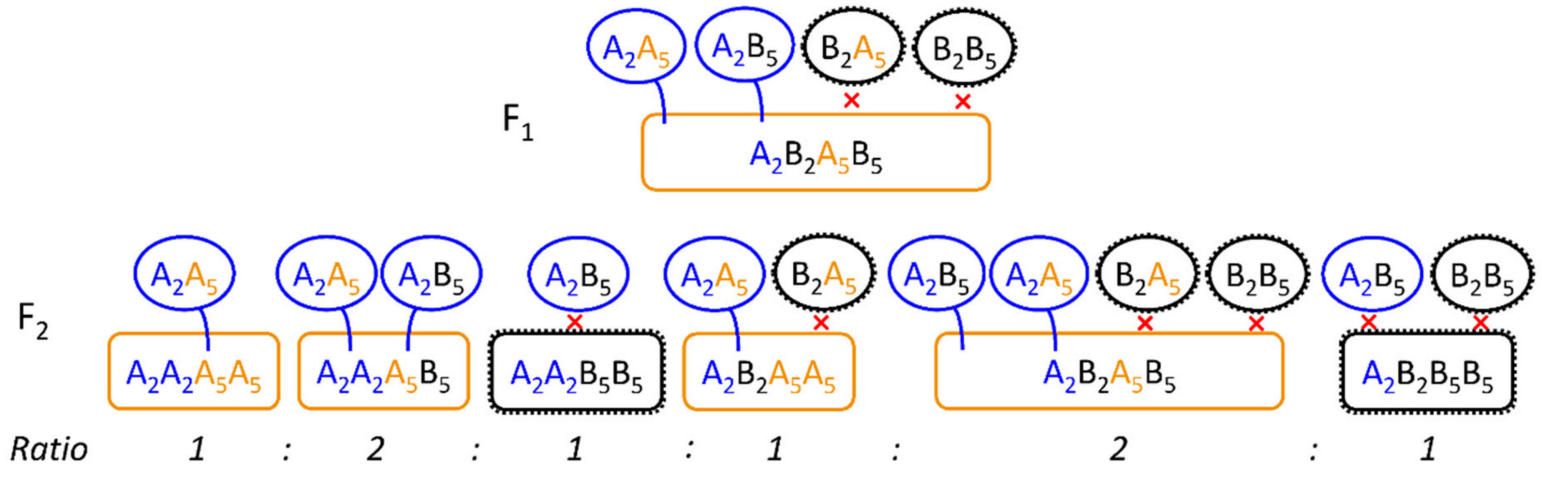

Figure 6. Visualization of self-fertility hypothesis for locus S2 (Z) and S5 (subscript 2 and 5) with the respective parental alleles for the inbred line (A) and self-incompatible genotype (B). The hypothesis displayed here was that both, pollen and stigma, carry proteins or any structure (black) on the surface that was responsible for the self-incompatibility mechanism. Those structures were expressed by a respective allele at each (multiallelic) locus. The $Z$ locus was causal for the pollen (circles) and the $S$ locus for the stigma (rounded rectangles). Self-fertility $(S f)$ could have been expressed by a mutation at each locus (pollen = blue, stigma = orange) that resulted in no or a special (protein) structure causing, if matched with a similar or complementary structure on the opposite surface (= two colored surfaces), successful pollination. Because the pollen was haploid and the stigma diploid, the $Z$ alleles segregated 1:1 $\left(A_{2} A_{2}: A_{2} B_{2}\right)$ and the $S 5$ alleles 1:2:1 $\left(A_{5} A_{5}: A_{5} B_{5}: B_{5} B_{5}\right)$ and the ratio of the combination of both loci is displayed in the figure. The $S f$ allele for the stigma (S5) was dominant.

Previous studies were mainly based on marker segregation [25,27] and in further inbreeding generations, the alleles for the S5 locus would theoretically deviate more and more from a 1:1 ratio (of randomly segregating parental alleles), because certain genotypes could not be self-pollinated (Figure 6). In the $\mathrm{F}_{3}$ generation, therefore, we would expect an average ratio of the $S 5$ alleles of $\mathrm{A}: \mathrm{H}: \mathrm{B}=3: 2: 1$ (= 2:1 ratio of parental alleles $\mathrm{A}$ and $\mathrm{B})$. Due to excess of pollen, the macrogametes could be successfully self-pollinated even when the $Z$ locus was heterozygous so that the interaction between both loci could (principally) not be validated on marker basis. If we assume that there were only two target sides (pollen or stigma surface) affected by expressed $S f$ alleles, it may even be possible that there were more (stigma-based) self-incompatibility loci segregating in this population, that could not be detected because they were masked by the $Z$ and the $S 5$ locus. Further, the high amount of explained genetic variation of the $S 5$ locus indicated that the lack of fertility was mainly dependent on self-incompatibility and not on chromosomal abnormalities and the additional QTLs we detected could also be additional self-incompatibility loci. For the identification of reasons for fertility other than self-incompatibility, additional studies of pollen vitality or germination, as done in early studies [12], could also help to better assess non-fertility. In this study, (extremely) sterile plants could also be caused by pollen sterility instead of self-incompatibility that we did not investigate. Unintentionally, the self-incompatibility loci were also selection factors for perenniality. As discussed before, the unintentional selection at the $Z$ locus may have even helped to select crosses with "advanced" perennial genotypes. The second self-incompatibility locus S5 could additionally help to shorten the distance to QTL-P5, because it explained 0.35 of the genetic covariance between non-fertility and perenniality (Table 2). Though, in following 
generations the most-fertile and most perennating genotypes must be selected. A random continuous self-pollination could otherwise result in a reduction of perennial genotypes.

\subsection{Perenniality}

To the best of our knowledge, this is the first mapping study for perenniality in rye. We could show, that perenniality was not caused by a single major gene like it was proposed by Dierks and Reimann-Phillip [19] and five QTLs could be located on chromosomes $2 R, 3 R, 4 R, 5 R$ and $7 R$ that in combination explained 0.74 of the genetic variance. All identified QTLs were highly additive so that three of them, QTL-P4, QTL-P5 and QTL-P7, with the highest explained genetic variance, each ranging from 0.16 to 0.24 may be most interesting for breeding. However, a fixation of three QTLs simultaneously would require large population sizes and for the marker-defined clusters still a large variation between the genotypes was observed (Figure 5a). Future (backcross) populations with defined marker combinations must proof potential redundancy of the identified QTLs (genes) and whether the number of QTLs for perenniality could be reduced to still reach a high trait level. We additionally tried to estimate marker-marker interaction but concluded that it was not significant. Here, the adjustment of the genome-wide error might had been too strict. With the given method for adjustment [43] it was computationally not possible to enter all marker-marker interactions into a PCA and calculate the effective marker number from it directly. Thus, we used the number of all possible combinations of effective markers from the single marker fit as effective marker number $\left(=q_{\text {eff }}\left(q_{\text {eff }}-1\right)\right)$ for the global-threshold adjustment of the marker-marker interactions. Additionally, the incremental fit of the fixed model effects reduced the power for the (lastly fitted) marker-marker effects and hence most probably, the procedure was generally over-adjusted. An example for epistasis could be found in rice where a dominant complementary gene action for $R h z 2$ and $R h z 3$ was concluded [31].

Aside from the genetic complexity, the trait was also dependent on the environment. This was shown by large genotype-location interaction (Table 1) and could be explained, by the expression of the perennial phenotype by several genes, of which each could be differently affected by environment. If we would split up the trait perenniality (and the environment) into more factors, like number of axillary buds (shoots), general number of tillers or sensitivity to vernalization, we may probably gain a better understanding of the different genetic and environmental factors. In this study, multi-environment trials were limited by the use of the $F_{2}$ generation that we had chosen to reduce the influence of (at this point) unknown fertility reasons. With further inbreeding generations, more seeds would be available to replicate a single genotype (line) in several environments. To still not neglect this issue, we vegetatively cloned the single genotypes, resulting in plants strong enough to be tested in two (ecologically highly) different environments.

\subsection{Species Synteny}

To our knowledge, this was the first mapping study of perenniality in rye, but in other cereals perenniality has already been mapped and even further, certain loci could be connected across species (e.g., in rice, sorghum, teosinte, Leymus-wildrye) by comparing gene, marker or protein sequences $[30-32,35,37,38,40,44,45]$. Because rye was generally shown to be highly syntenic to some of those species [46,47], it could be interesting to compare our results with the other species. However, on a phenotypic level, the perenniality in our study differed from the other crops, because there, perennial genotypes were simultaneously characterized by rhizomatous growth. On a genomic level, it was difficult to make proper comparisons, because so far for rye only reference genome sequences for the annual crop (S. cereale) had been published $[47,48]$ and functional perennation genes could principally only be found in genomes of perennial species (genotypes). If we expect similar genes for perenniality across cereals, the comparison of genomic sequences from perennation-associated QTLs in perennial species could be a valuable resource to dissect perennation from related traits and to filter the vast amount of potential gene candidates. 
The sequence of perennial rice, Oryza longistaminata, was already published [49] and perennial sorghum, Sorghum propinquum, was mentioned to be sequenced [45]. To our knowledge, research on perennation in the closest rye relatives, wheat (Triticum aestivum) and barley (Hordeum vulgare) ended with crosses between crop and wild relative [50,51]. In terms of basic knowledge of perenniality, studies of the model plant Arabidopsis thaliana or better its perennial relative Arabis alpina were also useful. A perenniality-related flowering gene was identified [52] and the study showed that flowers of Arabis alpina developed from the main shot and the axillary buds (meristems) were most important for the perennial life cycle. Another study [53] showed that the axillary buds that were developed at a distance from the shoot apical meristem (SAM) and before the onset of vernalization, remained dormant during flowering and this was the prerequisite for perenniality. Caused by vernalization and the following determination of the SAM into flowers, also axillary buds in proximity were developed and their fate of vegetative growth (in the first flowering period) was determined. This showed, that one key mechanism for perenniality was the conservation of axillary buds and consequently the isolation or even protection from plant hormones triggering flower induction and later senescence. The fact, that axillary buds were developed before flowering showed that plant resources were invested into the vegetative growth (instead of seed set) before flowering and seed yield reduction due to perenniality would mainly be caused by less (dense) tillers compared to annual plants. An important question would be, to what extent the roots were affected by the senescence of flowering shoots and how the plant can reach new nutrients, especially when plants cannot spread out by rhizomatous growth like in perennial rye. It was also shown that environmental factors like the duration of cold treatment influenced the percentage of plants that showed senescence after seed set [53].

\subsection{Breeding Perspectives}

Compared to the trait fertility, which could be reduced to a single self-incompatibility locus, perenniality remained a complex topic in which we, as a first step, identified QTLs for perenniality in rye. The trait also showed high genotype-environment interaction. In comparison to our experimental set up with intensively cherished single-plant growing practice, more farming-like practices with field plots previously showed worse results in the degree of perenniality. When perennial genotypes were grown in large-drilled yield plots, the regrowth in the second year was much lower compared to a single plant growing practice and the yield of the perennial progenies was reduced compared to annual rye sown a second time in the same plot [54] illustrating that intense intra-plot competition negatively affects perenniality. Perennial rye varieties were better suited for dual purpose use (grain + biomass), grazing or mixed cropping $[3,5,54]$ and it is probable that such practical challenges would also appear in other perennial cereals like wheat or barley as soon as they reach higher breeding progress. In wheat, the progress was challenged by the hexaploid karyotype of wheat combined with the diploid or tetraploid karyotype of the perennial (Thinopyrum, Leymus) species [35,51]. Recombination between the genomes was lacking and as a solution amphiploid wheat was discussed to serve as potential new breeding pool [55], but has previously also been found as impractical [56]. Generally, all species comparisons highlighted that perenniality must be well defined [57] and also for rye the differences in the phenotype could be refined for more detailed studies. Especially with a focus on future breeding efforts, the identification of perenniality-related plant structures like dormant buds or shoots in the young rye plants could be a powerful selection criterion and allow the trait perenniality to be assessed even before flowering and hence to shorten the breeding cycle.

Aside from breeding perennial varieties, perenniality may be interesting as an additional tool for rye breeding. The conservation of single plants over several years without development of inbred lines would allow to implement new breeding strategies, especially for population breeding. By means of polycross or (incomplete) diallel methods [58,59] the combining ability of a single genotype (plant) could be estimated from its offspring 
after crossing with a tester population and based on it, superior (perennial) plants could be intercrossed after the two-year testing procedure to build up a new improved population. Such a methodology was so far only possible by special short-day cultivation practices keeping clones of the plants in a vegetative state alive over several years that was in practice not very successful $[60,61]$. Later on, in vitro propagation of single rye plants was tried, but after the long storage period under cold conditions the plants quickly switched into the generative stage resulting in one or a few tillers only and thus restricting seed availability. Beside this special breeding purpose, the largest potential of perennial rye was to use it as genetic resource for trait introgression into cultivated (hybrid) rye, because we observed a good resistance to leaf rust (Puccinia recondita) and stem rust (P. graminis f.sp. secalis).

\section{Materials and Methods}

\subsection{Breeding Material}

Breeding material of a self-incompatible perennial rye population originally derived from a cross $S$. cereale $\times$ S. strictum was received from Reimann-Philipp who selected for high levels of fertility and perennation over several cycles. Several plants thereof were crossed plant-wise with a self-fertile breeding line of the hybrid rye program of the University of Hohenheim (L301-N) in the greenhouse in 2014. From the resulting $\mathrm{F}_{1}$ plants (sown in autumn 2014), the most fertile single plant with high perenniality was self-pollinated under an isolation bag (in 2015) resulting in the $\mathrm{F}_{2}$ population 'L301-N $\times$ $84 / 1^{\prime}$ that derived from a single gamete of the perennial rye population. We had to analyze this $F_{2}$ population and could not self the population subsequently (e.g., by single-seed descent), because otherwise the non-fertile plants would have been eliminated equaling a strong (natural) selection and producing a bias to our mapping population given the correlation of fertility and perenniality.

\subsection{Field Trials}

In autumn 2015, the $\mathrm{F}_{2}$ population was sown in trays and transplanted in pots after having 2-3 leaves. When the plants (= genotypes) produced enough axillary shoots (tillers), 200 plants were vegetative cloned (ripped apart) resulting in four clones per genotype. Two clones of each genotype were planted as replicates in the field located in Stuttgart-Hohenheim $\left(48^{\circ} 42^{\prime} 54^{\prime \prime} \mathrm{N} 9^{\circ} 11^{\prime} 22^{\prime \prime} \mathrm{E}, 389 \mathrm{~m}\right.$ above sea level, mean annual temperature $10.1^{\circ} \mathrm{C}$, mean annual precipitation $691 \mathrm{~mm}$ ) and two clones at 'Oberer Lindenhof' $\left(48^{\circ} 28^{\prime} 26^{\prime \prime} \mathrm{N} 9^{\circ} 18^{\prime} 18^{\prime \prime} \mathrm{E}, 720 \mathrm{~m}\right.$ above sea level, mean annual temperature $6.8^{\circ} \mathrm{C}$, mean annual precipitation $942 \mathrm{~mm}$ ) close to Würtingen (St. Johann, Germany). We used spaced planting with a distance of $0.25 \mathrm{~m}$ from each neighboring plant. The genotypes plus some checks were grown in two randomized complete blocks at each location. The plants flowered in 2016, seeds were harvested subsequently and the plants cut by hand to 20-30 cm above the ground, so that perenniality (plant regrowth) could be assessed some weeks later according to the following.

Perenniality was assessed on a 0 to 9 scale, indicating the amount of new arising tillers in relation to the remaining stubble from the initial shoots. Zero indicated no regrowth of the plant and nine a full regrowth resulting in about the same number of tillers as remaining stubbles from harvest. To prevent false scorings due to germinated seeds that fell out by threshing, the plots were cleaned with a commercial leaf blower after harvest. In Hohenheim, the seed set or better non-seed set ("Schartigkeit") of the heads was visually scored as percentage $(0-100 \%)$ of florets that did not develop seeds (in comparison to the seed set of non-perennial self-fertile rye grown as check). Consequently, fully sterile plants were scored with $100 \%$ non-seed set and fully fertile (like standard self-fertile rye) were rated with $0 \%$ non-seed set. To simplify the wording throughout the paper, we calculated the fertility by $100 \%$ minus non-seed set and used this term instead. 


\subsection{Marker Analysis and Linkage Map Construction}

From the $\mathrm{F}_{2}$ population, 182 genotypes and the respective parents were used for marker analysis. The DNA was extracted from about $4-5 \mathrm{~cm}$ long, dried leaf samples using the Macherey and Nagel (Düren, Germany) NucleoSpin 96 Plant II DNA extraction kit. Marker analysis was done with a proprietary rye 10K Infinium iSelect SNP chip at KWS SAAT SE and Co. KGaA, Grimsehlstr. 31, 37555 Einbeck, Germany. The SNPs of this assay were partially overlapping with the 5k-SNP assay of Martis et al. [46] and the 600k-SNP assay of Bauer et al. [41]. Only segregating markers were kept and coded as ABH (parent1, parent2, heterozygous). When one of the parents had a missing or heterozygous marker allele, the other parent was used as reference for $\mathrm{ABH}$ coding. If marker alleles were heterozygous and/or missing for both parents, the markers were dropped from the data frame. Additionally, markers with more than 10 percent missing values were dropped, resulting in 2641 markers of which 2314 were correlated with one (= redundant) in several combinations so that only a single marker thereof (with least missing values) was kept for further analysis, resulting in 789 unique markers. Those markers had $0.1 \%$ missing values on average and were imputed with the "imputeByFlanks" function from the R package ABHgenotypeR [62]. After this, still seven missing values remained in the data. Those were imputed manually. For linkage map construction we used the non-imputed data and included the redundant markers as they were located at the same position anyway, but allowed a better comparison of markers with the already published linkage map from Bauer et al. [41]. The linkage map was constructed using the R package ASmap and the "mst.map" function with "Kosambi" method [63,64]. Based on marker data, two genotypes were identified as being identical, each to a further one. The duplicates (one genotype per duplicate) were removed for linkage map construction and marker studies. For mapping, both duplicates (two genotypes per duplicate) were removed.

\subsection{Phenotypic Analysis and Mapping Procedure}

Phenotypic means were calculated by using mixed models implemented in the software ASReml for R [64,65]. Given by the experimental structure the model (1) was $y_{i j k l}=\mu$ $+g_{i}+l_{j}+r_{j k}+(g l)_{i j}+e_{i j k l}$, with the observation $y_{i j k l}$ explained by the overall intercept $\mu$ and effects for the $i$ th genotype $g$, which was modelled as fixed for best linear unbiased estimators (BLUEs) and as random to estimate variance components, and the further random effects for the $j$ th location $l$, the $k$ th replicate (= cloned plant) $r$ nested within the location, the genotype-location interaction $(g l)_{i j}$ and the error term $e_{i j k l}$. As the fertility was only assessed in a single location, the location effect and the respective interactions were not fitted for this trait. The heritability was calculated by $H^{2}=\sigma_{g}{ }^{2} /\left(\sigma_{g}{ }^{2}+a v \cdot V D / 2\right)$, where $\sigma_{g}^{2}$ is the genetic variance and av.VD the mean variance of a difference of two BLUEs [66].

The QTL-mapping procedure was based on single marker regression fitting each marker as codominant (first) and as dominant (second) fixed effect. The codominant (cd) markers were coded as 0, 1, $2(\mathrm{~A}, \mathrm{H}, \mathrm{B})$ and the dominant (d) as 0, 1, 0. For the trait perenniality, also random effects for the (cd and d) marker-location interactions were fitted. For each (fixed) effect the $p$-value was extracted from a Wald-test statistic of the fixed effects. Additionally, a $p$-value for the combination of both effects was calculated by adding up the (incremental) Wald-statistics of both effects and calculating $p$-values based on Chi-square statistics with and adjusted number of degrees of freedom $(\mathrm{df}=2)$. The global significance threshold was calculated by the simpleM method [43]. Comparable with Bonferroni correction, the defined genome-wide significance threshold $\alpha=0.05$ was divided by the number of tests (markers) $q$ in order to obtain the SNP-wise significance level. Due to correlation of the markers, the tests were not independent and $\alpha$ was divided by an effective number of markers $q_{\text {eff }}$ instead. The effective number of markers $q_{\text {eff }}$ was calculated by running a principal component analysis (PCA) based on the marker data and the number of eigenvalues that explained $99.5 \%$ of the variation of the SNP data. PCA was based on a correlation matrix of the markers coded in 0, 1, 2 (A, H, B) and calculated by using the "eigen" function in R [64]. The procedure was initially developed for genome-ide 
association studies (GWAS) [43] and we considered the linkage mapping as special case of GWAS resulting in an even smaller number qeff due to the high linkage of markers, compared to GWAS studies.

To adjust for masking effects of genes located on other chromosomes than the single marker in the fit, we additionally run two scans with models including markers (cd and d) as fixed cofactors fitted in the model sequence before the actual marker under testing (cofactor-based mapping, CM). The two additional scans differed in terms of the cofactor selection. For the first additional scan CM1, from each chromosome the most significant markers were chosen, that passed the global significance threshold in a cofactor-free scan (compare [67]). For the second additional scan (CM2), a simultaneous forward- and backward-selection procedure was used to identify the respective cofactors. For simplicity reasons and computational speed, this procedure was based on a linear model including only the BLUEs and markers in cd coding. The procedure was implemented as "steps" function in R [64]. We started the procedure with a Null model (only intercept) and used the (Schwarz) Bayesian information criterion (BIC) [68] by setting $k=\log \left(\mathrm{N}_{\text {genotypes }}\right)$. Similar to the single marker regression without cofactors, $p$-values for $\mathrm{cd}$ and $\mathrm{d}$ marker effects were extracted from the Wald-test statistics.

For all markers identified as significant we calculated effect sizes plus standard errors from the estimated coefficients and coefficient error variance. The explained genetic variance $\mathrm{p}_{\mathrm{G}}$ was calculated as reduction in the genetic variance estimated in the phenotypic model (1) by additional marker effects, divided by the full genetic variance estimated in model (1). We additionally ran a bivariate model including both, perenniality and non-fertility in one model. We fitted random effects with unstructured variance-covariance matrix for the genotype and the residual and with diagonal variance-covariance matrix for the replicate. Only data with records from both traits was used and thus no location effect was fitted. Similar to $\mathrm{p}_{\mathrm{G}}$, the explained genetic covariance $\mathrm{p}_{\mathrm{CovG}}$ was calculated as reduction in the genetic covariance estimated in the bivariate phenotypic model by additional marker effects divided by the full genetic covariance estimated in in the bivariate phenotypic model.

To detect potential epistasis of marker1 (m1) with marker2 (m2), a scan with all marker-marker interactions and possible $d$ and cd combinations was run. The (incremental) sequence of fixed effects was the following: $m 1_{c d}+m 2_{c d}+m 1_{d}+m 2_{d}+m 1_{c d}: m 2_{c d}+$ $\mathrm{m} 1_{\mathrm{d}}: \mathrm{m} 2_{\mathrm{d}}+\mathrm{m} 1_{\mathrm{d}}: \mathrm{m} 2_{\mathrm{cd}}$. The $\mathrm{m} 1_{\mathrm{d}}: \mathrm{m} 2_{\mathrm{cd}}$ interaction was tested also vice versa $\left(\mathrm{m} 2_{\mathrm{d}}: \mathrm{m} 1_{\mathrm{cd}}\right)$. No additional cofactors were used in this run, but for the trait perenniality all fixed marker effects were additionally fitted as random marker-location interactions. We defined the $q_{\text {eff }}$ for global significance threshold of epistasis effects as product of $\mathrm{q}_{\mathrm{eff}}$ and $\left(\mathrm{q}_{\mathrm{eff}}-1\right)$ as this would be the number of all possible combinations. Due to the high number of markermarker combinations tested $(n=621,732)$ we did not run a PCA and not deduced $\mathrm{q}_{\text {eff }}$ specifically for the interactions.

\section{Conclusions}

We could show that perenniality in rye was quantitatively inherited and we identified five QTLs with medium effect sizes of which some acted dominantly. This quantitative nature could be challenging for breeding of perennial rye and if breeders aim for perennial varieties, future studies should investigate the impact of the environment and to what extent selection on perenniality-related plant structures or with molecular markers could shorten breeding cycles. Reduced fertility was related to cytogenetic causes in previous studies. We could show, that in our material it was mainly related to self-incompatibility by identifying a locus that explained 0.64 of the genetic variance and is most probably the S5 locus, known from other studies. If the self-incompatibility is considered consequently, reduced fertility should not be a concern in future breeding programs.

Supplementary Materials: The following are available online at https: / www.mdpi.com/article / 10.3390/plants10061210/s1, Table S1 DNA sequences of the reported markers; Figure S1 Pearson correlation of markers; Figure S2 LOD scores for mapping the phenotype perenniality by single 
marker regression; Figure S3 LOD scores for mapping the phenotype perenniality by single marker regression and using additional markers from cofactor selection as cofactors; Figure S4 LOD scores for mapping the phenotype perenniality by single marker regression and using additional markers from a first run as cofactors; Figure S5 LOD scores for mapping the phenotype fertility by single marker regression; Figure S6 LOD scores for mapping the phenotype fertility by single marker regression and using additional markers from cofactor selection as cofactors; Figure S7 LOD scores for mapping the phenotype fertility by single marker regression and using additional markers from a first fit as cofactors; Figure S8 Genotype means for the trait perenniality clustered by marker alleles; Figure S9 Display of codominant-codominant marker-marker interaction of mapping perenniality; Figure S10 Display of dominant-dominant marker-marker interaction of mapping perenniality; Figure S11 Display of codominant-dominant marker-marker interaction of mapping perenniality; Figure S12 Display of codominant-codominant marker-marker interaction of mapping fertility; Figure S13 Display of dominant-dominant marker-marker interaction of mapping fertility; Figure S14 Display of codominant-dominant marker-marker interaction of mapping fertility.

Author Contributions: P.G. analyzed the data and wrote the manuscript. T.M. conceived the study, supervised the project and edited the manuscript. All authors have read and agreed to the published version of the manuscript.

Funding: Marker analyses were funded by a special budget of the University of Hohenheim (TG77). The first author was funded by the German Federal Ministry for Economic Affairs and Energy (BMWi, grant \# IGF-Nr. 246 EBG) via AiF (Arbeitsgemeinschaft industrieller Forschungsvereinigungen "Otto von Guericke" e.V. Cologne) and Gemeinschaft zur Förderung von Pflanzeninnovation e. V., Bonn, Germany (GFPi), Bonn (G163/19 AiF), in the framework of the CORNET (Collective Research Networking) program ProtectRye.

Institutional Review Board Statement: Not applicable.

Informed Consent Statement: Not applicable.

Data Availability Statement: The SNP marker chip we used in this study was proprietary to KWS SAAT SE and Co. KGaA and thus the marker data is not publicly available. Marker sequences for the most important markers can be found in the Supplementary Table S1 and were additionally referenced on a previously published linkage map [41]. Seeds for perennial rye genotypes can be requested from the corresponding author. The material used in this study was not maintained.

Acknowledgments: We cordially thank Mark Raith for conducting the field trials and doing the assessments and the whole technical staff of the rye group for assistance.

Conflicts of Interest: The authors declare no conflict of interest.

\section{References}

1. FAO. FAOSTAT. Available online: http://www.fao.org/faostat/en/\#data/QC (accessed on 13 January 2021).

2. Frederiksen, S.; Petersen, G. A Taxonomic Revision of Secale (Triticeae, Poaceae). Nord. J. Bot. 1998, 18, 399-420. [CrossRef]

3. Füle, L.; Galli, Z.; Kotvics, G.; Heszky, L. Forage Quality of 'Perenne', a New Perennial Rye Variety (Secale cereale x Secale montanum). In Genetic Variation for Plant Breeding, Proceedings of the 17th EUCARPIA Congress, Tulln, Austria, 8-11 September 2004; BOKU_University of Natural Resources and Applied Life Sciences: Vienna, Austria; Tulln, Austria, 2004 ; pp. 435-438.

4. Acharya, S.N.; Mir, Z.; Moyer, J.R. ACE-1 Perennial Cereal Rye. Can. J. Plant Sci. 2004, 84, 819-821. [CrossRef]

5. Halász, E.; Sipos, T. Perennial Rye (Secale cereanum) Breeding in Hungary, at University of Debrecen. An. Univ. din Oradea Fasc. Protecția Mediu. 2007, 12, 57-62.

6. Oram, R.N. Secale montanum-A Wider Role in Australasia? N. Z. J. Agric. Res. 1996, 39, 629-633. [CrossRef]

7. Reimann-Philipp, R. Perennial Spring Rye as a Crop Alternative. J. Agron. Crop Sci. 1986, 157, 281-285. [CrossRef]

8. Reimann-Philipp, R. Breeding Perennial Rye. Plant Breed. Rev. 1995, 13, 265-292.

9. Kotvics, G. Investigation on increasing the protein content of Secale cereale L. In Protein Growth by Plant Breeding; Akadémiai Kiadó: Budapest, Hungary, 1970; pp. 89-98.

10. Andersen, M.R.; Depuit, E.J.; Abernethy, R.H.; Kleinman, L.H. Value Mountain Rye for Suppression of Annual Bromegrasses on Semiarid Mined Lands. J. Range Manag. 1992, 45, 345-351. [CrossRef]

11. Tang, Z.X.; Ross, K.; Ren, Z.L.; Yang, Z.J.; Zhang, H.Y.; Chikmawati, T.; Gustafson, M.; Secale, J.P. Wild Crop Relatives: Genomic and Breeding Resources: Cereals; Kole, C., Ed.; Springer: Berlin/Heidelberg, Germany, 2011; pp. 367-396. ISBN 978-3-642-14228-4.

12. Schiemann, E.; Nürnberg-Krüger, U. Neue Untersuchungen an Secale africanum Stapf. Naturwissenschaften 1952, 39, 136-137. [CrossRef]

13. Riley, R. The Cytogenetics of the Differences between Some Secale Species. J. Agric. Sci. 1955, 46, 377-383. [CrossRef] 
14. Khush, G.S.; Stebbins, G.L. Cytogenetic and Evolutionary Studies in Secale. I. Some New Data on the Ancestry of S. Cereale. Am. J. Bot. 1961, 48, 723-730. [CrossRef]

15. Stutz, H.C. On the Origin of Cultivated Rye. Am. J. Bot. 1972, 59, 59-70. [CrossRef]

16. Singh, R.J.; Röbbelen, G. Identification by Giemsa Technique of the Translocations Separating Cultivated Rye from Three Wild Species of Secale. Chromosoma 1977, 59, 217-225. [CrossRef]

17. Singh, R.J. Cross Compatibility, Meiotic Pairing and Fertility in 5 Secale Species and Their Interspecific Hybrids. Cereal Res. Commun. 1977, 5, 67-75.

18. Stutz, H.C. A Cytogenetic Analysis of the Hybrid Secale cereale L. $\times$ Secale montanum Guss. and Its Progeny. Genetics 1957, 42 , 199-221. [CrossRef] [PubMed]

19. Dierks, W.; Reimann-Philipp, R. Die Züchtung eines perennierenden Roggens als Möglichkeit zur Verbesserung der Roggenzuchtmethodik und zur Schaffung eines mehrfach nutzbaren Grünfutter- und Körnerroggens. Z. Pflanzenzucht 1966, $343-368$.

20. Ossent, H.P. Perennierender Kulturroggen. Der Züchter 1930, 2, 221-227. [CrossRef]

21. Lundqvist, A. Self-Incompatibility in Rye I. Genetic Control in the Diploid. Hereditas 1956, 42, 293-348. [CrossRef]

22. Wricke, G.; Wehling, P. Linkage between an Incompatibility Locus and a Peroxidase Isozyme Locus (Prx 7) in Rye. Theor. Appl. Genet. 1985, 71, 289-291. [CrossRef]

23. Gertz, A.; Wricke, G. Linkage between the Incompatibility Locus Z and a $\beta$-Glucosidase Locus in Rye. Plant Breed. 1989, 102, 255-259. [CrossRef]

24. Hackauf, B.; Wehling, P. Approaching the Self-Incompatibility Locus Z in Rye (Secale cereale L.) via Comparative Genetics. Theor. Appl. Genet. 2005, 110, 832-845. [CrossRef]

25. Fuong, F.T.; Voylokov, A.V.; Smirnov, V.G. Genetic Studies of Self-Fertility in Rye (Secale cereale L.). 2. The Search for Isozyme Marker Genes Linked to Self-Incompatibility Loci. Theor. Appl. Genet. 1993, 87, 619-623. [CrossRef]

26. Voylokov, A.V.; Korzun, V.; Börner, A. Mapping of Three Self-Fertility Mutations in Rye (Secale cereale L.) Using RFLP, Isozyme and Morphological Markers. Theor. Appl. Genet. 1998, 97, 147-153. [CrossRef]

27. Voylokov, A.V.; Fuong, F.T.; Smirnov, V.G. Genetic Studies of Self-Fertility in Rye (Secale cereale L.). 1. The Identification of Genotypes of Self-Fertile Lines for the Sf Alleles of Self-Incompatibility Genes. Theor. Appl. Genet. 1993, 87, 616-618. [CrossRef] [PubMed]

28. Do Canto, J.; Studer, B.; Lubberstedt, T. Overcoming Self-Incompatibility in Grasses: A Pathway to Hybrid Breeding. Theor. Appl. Genet. 2016, 129, 1815-1829. [CrossRef]

29. Melz, G.; Kaczmarek, J.; Szigat, G. Genetical Analysis of Rye (Secale cereale L.). Location of Self-Fertility Genes in Different Inbred Lines. Genet. Pol. 1990, 31, 1-7.

30. Paterson, A.H.; Schertz, K.F.; Lin, Y.R.; Liu, S.C.; Chang, Y.L. The Weediness of Wild Plants: Molecular Analysis of Genes Influencing Dispersal and Persistence of Johnsongrass, Sorghum halepense (L.) Pers. Proc. Natl. Acad. Sci. USA 1995, 92, 6127-6131. [CrossRef]

31. Hu, F.Y.; Tao, D.Y.; Sacks, E.; Fu, B.Y.; Xu, P.; Li, J.; Yang, Y.; McNally, K.; Khush, G.S.; Paterson, A.H.; et al. Convergent Evolution of Perenniality in Rice and Sorghum. Proc. Natl. Acad. Sci. USA 2003, 100, 4050-4054. [CrossRef] [PubMed]

32. Westerbergh, A.; Doebley, J. Quantitative Trait Loci Controlling Phenotypes Related to the Perennial versus Annual Habit in Wild Relatives of Maize. Theor. Appl. Genet. 2004, 109, 1544-1553. [CrossRef]

33. Chen, Z.; Hu, F.; Xu, P.; Li, J.; Deng, X.; Zhou, J.; Li, F.; Chen, S.; Tao, D. QTL Analysis for Hybrid Sterility and Plant Height in Interspecific Populations Derived from a Wild Rice Relative, Oryza longistaminata. Breed. Sci. 2009, 59, 441-445. [CrossRef]

34. Zhao, J.; Li, J.; Xu, P.; Zhou, J.; Hu, F.; Deng, X.; Deng, W.; Tao, D. A New Gene Controlling Hybrid Sterility between Oryza sativa and Oryza longistaminata. Euphytica 2012, 187, 339-344. [CrossRef]

35. Yun, L.; Larson, S.R.; Mott, I.W.; Jensen, K.B.; Staub, J.E. Genetic Control of Rhizomes and Genomic Localization of a Major-Effect Growth Habit QTL in Perennial Wildrye. Mol. Genet. Genom. 2014, 289, 383-397. [CrossRef]

36. Fan, Z.; Wang, K.; Rao, J.; Cai, Z.; Tao, L.-Z.; Fan, Y.; Yang, J. Interactions among Multiple Quantitative Trait Loci Underlie Rhizome Development of Perennial Rice. Front. Plant Sci. 2020, 11, 1757. [CrossRef]

37. Jang, C.S.; Kamps, T.L.; Skinner, D.N.; Schulze, S.R.; Vencill, W.K.; Paterson, A.H. Functional Classification, Genomic Organization, Putatively Cis-Acting Regulatory Elements, and Relationship to Quantitative Trait Loci of Sorghum Genes with Rhizome-Enriched Expression. Plant Physiol. 2006, 142, 1148-1159. [CrossRef]

38. Hu, F.; Wang, D.; Zhao, X.; Zhang, T.; Sun, H.; Zhu, L.; Zhang, F.; Li, L.; Li, Q.; Tao, D.; et al. Identification of Rhizome-Specific Genes by Genome-Wide Differential Expression Analysis in Oryza longistaminata. BMC Plant Biol. 2011, 11, 1-14. [CrossRef]

39. He, R.; Salvato, F.; Park, J.-J.; Kim, M.-J.; Nelson, W.; Balbuena, T.S.; Willer, M.; Crow, J.A.; May, G.D.; Soderlund, C.A.; et al. A Systems-Wide Comparison of Red Rice (Oryza longistaminata) Tissues Identifies Rhizome Specific Genes and Proteins That Are Targets for Cultivated Rice Improvement. BMC Plant Biol. 2014, 14, 1-21. [CrossRef]

40. Zhang, Y.; Zhang, S.; Liu, H.; Fu, B.; Li, L.; Xie, M.; Song, Y.; Li, X.; Cai, J.; Wan, W.; et al. Genome and Comparative Transcriptomics of African Wild Rice Oryza longistaminata Provide Insights into Molecular Mechanism of Rhizomatousness and Self-Incompatibility. Mol. Plant 2015, 8, 1683-1686. [CrossRef] [PubMed]

41. Bauer, E.; Schmutzer, T.; Barilar, I.; Mascher, M.; Gundlach, H.; Martis, M.M.; Twardziok, S.O.; Hackauf, B.; Gordillo, A.; Wilde, P. Towards a Whole-genome Sequence for Rye (Secale cereale L.). Plant J. 2017, 89, 853-869. [CrossRef] 
42. Bolibok-Bragoszewska, H.; Targońska, M.; Bolibok, L.; Kilian, A.; Rakoczy-Trojanowska, M. Genome-Wide Characterization of Genetic Diversity and Population Structure in Secale. BMC Plant Biol. 2014, 14, 1-15. [CrossRef] [PubMed]

43. Gao, X.; Starmer, J.; Martin, E.R. A Multiple Testing Correction Method for Genetic Association Studies Using Correlated Single Nucleotide Polymorphisms. Genet. Epidemiol. 2008, 32, 361-369. [CrossRef]

44. Zhang, T.; Zhao, X.; Huang, L.; Liu, X.; Zong, Y.; Zhu, L.; Yang, D.; Fu, B. Tissue-Specific Transcriptomic Profiling of Sorghum propinquum Using a Rice Genome Array. PLoS ONE 2013, 8, e60202. [CrossRef] [PubMed]

45. Kong, W.; Kim, C.; Goff, V.H.; Zhang, D.; Paterson, A.H. Genetic Analysis of Rhizomatousness and Its Relationship with Vegetative Branching of Recombinant Inbred Lines of Sorghum bicolor $\times$ S. propinquum. Am. J. Bot. 2015, 102, 718-724. [CrossRef]

46. Martis, M.M.; Zhou, R.; Haseneyer, G.; Schmutzer, T.; Vrána, J.; Kubaláková, M.; König, S.; Kugler, K.G.; Scholz, U.; Hackauf, B Reticulate Evolution of the Rye Genome. Plant Cell 2013, 25, 3685-3698. [CrossRef]

47. Li, G.; Wang, L.; Yang, J.; He, H.; Jin, H.; Li, X.; Ren, T.; Ren, Z.; Li, F.; Han, X.; et al. A High-Quality Genome Assembly Highlights Rye Genomic Characteristics and Agronomically Important Genes. Nat. Genet. 2021. [CrossRef]

48. Rabanus-Wallace, M.T.; Hackauf, B.; Mascher, M.; Lux, T.; Wicker, T.; Gundlach, H.; Baez, M.; Houben, A.; Mayer, K.F.X.; Guo, L.; et al. Chromosome-Scale Genome Assembly Provides Insights into Rye Biology, Evolution and Agronomic Potential. Nat. Genet. 2021. [CrossRef]

49. Reuscher, S.; Furuta, T.; Bessho-Uehara, K.; Cosi, M.; Jena, K.K.; Toyoda, A.; Fujiyama, A.; Kurata, N.; Ashikari, M. Assembling the Genome of the African Wild Rice Oryza longistaminata by Exploiting Synteny in Closely Related Oryza Species. Commun. Biol. 2018, 1, 1-10. [CrossRef]

50. von Bothmer, R.; Flink, J.; Jakobsen, N.; Kotimäki, M.; Landström, T. Interspecific Hybridization with Cultivated Barley (Hordeum vulgare L.). Hereditas 1983, 99, 219-244. [CrossRef]

51. Jones, T.A.; Zhang, X.-Y.; Wang, R.R.-C. Genome Characterization of MT-2 Perennial and OK-906 Annual Wheat $\times$ Intermediate Wheatgrass Hybrids. Crop Sci. 1999, 39, 1041-1043. [CrossRef]

52. Wang, R.; Farrona, S.; Vincent, C.; Joecker, A.; Schoof, H.; Turck, F.; Alonso-Blanco, C.; Coupland, G.; Albani, M.C. PEP1 Regulates Perennial Flowering in Arabis alpina. Nature 2009, 459, 423-427. [CrossRef] [PubMed]

53. Ponraj, U.; Theres, K. Keep a Distance to Be Different: Axillary Buds Initiating at a Distance from the Shoot Apical Meristem Are Crucial for the Perennial Lifestyle of Arabis alpina. New Phytol. 2020, 227, 116-131. [CrossRef] [PubMed]

54. Miedaner, T.; Longin, F. St. John's rye-Efinitely too good for goats and sheep. In Neglected Cereals-From Ancient Grains to Superfood; ERLLING Verlag GmbH Co. KG: Clenze, Germany, 2017; pp. 111-122.

55. Curwen-McAdams, C.; Jones, S.S. Breeding Perennial Grain Crops Based on Wheat. Crop Sci. 2017, 57, 1172-1188. [CrossRef]

56. Banks, P.M.; Xu, S.J.; Wang, R.R.-C.; Larkin, P.J. Varying Chromosome Composition of 56-Chromosome Wheat $\times$ Thinopyrum intermedium Partial Amphiploids. Genome 1993, 36, 207-215. [CrossRef] [PubMed]

57. Munné-Bosch, S. Do Perennials Really Senesce? Trends Plant Sci. 2008, 13, 216-220. [CrossRef]

58. Falconer, D.S.; Mackay, T.F. Introduction to Quantitative Genetics, 4th ed.; Pearson-Prentice Hall: Harlow, UK, 2008.

59. Wellensiek, S.J. Rational Methods for Breeding Cross-Fertilizers. Meded. Landbouwhogesch. 1947, 7, 1-36.

60. Adam, J. Der Weg Zur Züchtung einer neuen Roggensorte. In Berichte Über Die Arbeitstagungen der "Arbeitsgemeinschaft der Saatzuchtleiter"; Bundesanstalt für Alpine Landwirtschaft: Admont, Austria, 1954; pp. 137-157.

61. Jungfer, E. Kurztagbehandelte Klone in der Roggenzüchtung. Der Züchter 1955, 25, 255-262. [CrossRef]

62. Reuscher, S.; Furuta, T. ABHgenotypeR: Easy Visualization of ABH Genotypes R package version 1.0.1. Available online: https: / /CRAN.R-project.org/package=ABHgenotypeR (accessed on 6 May 2021).

63. Taylor, J.; Butler, D. R Package ASMap: Efficient Genetic Linkage Map Construction and Diagnosis. J. Stat. Softw. 2017, 79, 1-29. [CrossRef]

64. R Core Team R: A Language and Environment for Statistical Computing; R Foundation for Statistical Computing: Vienna, Austria, 2019.

65. Butler, D. asreml: asreml() fits the linear mixed model. R package version 3.0. Available online: https://www.vsni.co.uk/ (accessed on 6 May 2021).

66. Piepho, H.-P.; Möhring, J. Computing Heritability and Selection Response from Unbalanced Plant Breeding Trials. Genetics 2007, 177, 1881-1888. [CrossRef] [PubMed]

67. Malosetti, M.; van Eeuwijk, F.A.; Boer, M.P.; Casas, A.M.; Elía, M.; Moralejo, M.; Bhat, P.R.; Ramsay, L.; Molina-Cano, J.-L. Gene and QTL Detection in a Three-Way Barley Cross under Selection by a Mixed Model with Kinship Information Using SNPs. Theor. Appl. Genet. 2011, 122, 1605-1616. [CrossRef]

68. Schwarz, G. Estimating the Dimension of a Model. Ann. Stat. 1978, 6, 461-464. [CrossRef] 